Yaym Geliş Tarihi: 07.06.2018

Yayına Kabul Tarihi: 02.07.2018

Online Yayın Tarihi: 17.08.2018

http://dx.doi.org/10.16953/deusosbil.431908
Dokuz Eylül Üniversitesi

Sosyal Bilimler Enstitüsü Dergisi

Cilt: 20, Say1: 2, Y11: 2018, Sayfa: 165-169

ISSN: 1302-3284 E-ISSN: 1308-0911

Araştırma Makalesi

\title{
İRAN TÜRK AĞIZLARINDA -ANA ZARF-FIIIL EKİ
}

Cihangir KIZILÖZEN*

$\ddot{O} z$

Bu incelemenin konusu, Iran Türk ağlzlarında kullanılan-AnA birleșik zarf-fiil eki ile ilgilidir. Azerbaycan ve Türkiye Türkçesi üzerine yapılan dilbilgisi çalışmalarında -Ana zarf-fiil eki yer almamaktadır. Kimi Iran Türk ă̆ızlarında kullanılan -Ana zarf-fiil eki, zaman bildiren zarf-fiil eki olup ölçünlü Türkiye Türkçesinde kullanılan -(y)IncA, -(U)ncA ve $-r,-A r,-x r \ldots-m A z$ birleşik zarf gruplarının işlevlerini yerine getirmektedir. Iran Türk ă̆ızlarında kullanılan -AnA ekinin bir zarf-fiil eki olup olmadı̆̆ durumuna Türkçenin birleşik zarf-fiil eki türetme yollarıyla bu ekin sözdizimindeki işlevlerinden hareketle açıklık getirilecektir. -AnA zarf-fiil ekinin kullanıldı̆̆ ă̆ızlarda -AnA + kimi/kimin birleşik zarf grubu da aynı işlevlerde kullanılmaktadır. Bu incelemede - AnA + kimi/kimin birleşik zarf grubu ile -AnA zarf-fiil ekinin hangisinin daha arkaik olduğu da ele alınmıştır.

Anahtar Kelimeler: -AnA Zarf-Fiil Eki, Iran Türk Ağızları, Birleşik Zarf-Fiil Ekleri, Halhal Ăgılar.

\section{THE GERUNDIVE SUFFIX -ANA IN TURKISH DIALECTS OF IRAN ${ }^{2}$}

\section{Abstract}

This study investigates the compound gerundive suffix -AnA in Turkish dialects of Iran. -AnA gerundive suffix indicates temporality and functions as -(y)IncA / -(y)UncA kadar ve $-r,-A r,-x r \ldots-m A z$ gerundive suffix groups of Standard Turkish of Turkish Republic. Here, it is aimed to answer if this suffix is a gerundive suffix or not by exploring the ways of constructing gerundive suffixes in Turkish. In the dialects having -AnA

Bu makale için önerilen kaynak gösterimi (APA 6. Sürüm):

Kızılözen, C. (2018). İran Türk ağızlarında -AnA zarf-fiil eki. Dokuz Eylül Üniversitesi Sosyal Bilimler Enstitüsü Dergisi, 20 (2), 165-169.

1 Bu inceleme, 25 Haziran 2010 tarihinde Ankara Üniversitesi, Dil ve Tarih-Coğrafya Fakültesi Çağdaş Türk Lehçeleri ve Edebiyatları Bölümü’nün düzenlediği "Türklük Araştırmaları Sempozyumu 2010 İran Türkolojisi: Konular, Sorunlar ve Yaklaşımlar" adlı sempozyumda sunulan ancak yayımlanmayan bildirinin genişletilmiş halidir.

* Dr. Öğr. Üyesi, Gümüşhane Üniversitesi, Edebiyat Fakültesi, Türk Dili ve Edebiyatı Bölümü, ORCID: 0000-0002-4202-1868, cahangir@gmail.com

2 This article has been presented as a paper at Ankara University, Faculty of Languages and History-Geography, at the symposium named "Türklük Araştırmaları Sempozyumu 2010 İran Türkolojisi: Konular, Sorunlar ve Yaklaşımlar" on June 25, 2010. 
gerundive suffix, the compound gerundive suffix group AnA + kimi/kimin is also used with the same function. This study also tries to find out which one of these suffixes is more archaic. Suffixes.

Keywords: -AnA Gerundive Suffix, Turkish Dialects of Iran, Compound Gerundive

\section{GIRIS}

İran'da Halaç, Türkmen, Kaşkayı ve Azerbaycan Türkçesi gibi Türk lehçeleri kullanılmaktadır. Azerbaycan Türkçesi ağızlarından Tebriz, Erdebil, Marağa, Mişkin** ve Halhal (Karini 2009: 199) ağızlarında kullanılan -AnA zarffiil eki, en çok kullanılan zarf-fiil eklerinden biridir. Bu ek, işlev bakımından ölçünlü Türkiye Türkçesinde kullanılan “-(y)IncA, (U)nca” (Korkmaz, 2003: 825) birleşik zarf-fiil eki görevini üstlenmektedir:

Arvad, kişi yelene ăgladı kor oldu. "Kadın, adam gelinceye kadar ăglayıp kör oldu" (Karini, 2009: 199-200). -AnA zarf-fiil ekinin bir diğer işlevi de tezlik bildirmekte olup ölçünlü Türkiye Türkçesinde kullanılan -r, -Ar,-xr... -mAz (Korkmaz, 2003: 827) zarf-fiil ekinin işlevini karşlamaktadır: Qoca emi ta qutarana, bi dene qeméynen virdl. "Yaşlı amca bitirir bitirmez kulıçla bir tane vurdu” (Karini, 2009: 199-200).

Önce Halhal ağızlarında bir birleşik zarf-fiil eki olarak tespit ettiğimiz AnA zarf-fiil ekinin gözlemlerimiz sonucunda Tebriz, Erdebil, Mişkin ve Marağa ağızlarında da aynı görevde kullanıldığını fark ettik. Söz konusu ağızlarda -AnA zarf-fiil ekiyle aynı görevi paylaşan bir başka dilbilgisel yapı da -AnA + kimi/kimin birleşik zarf-fiil grubudur. Bu yapıda -AnA zarf-fiil ekinden hemen sonra kimi/kimin "gibi" edatı gelmektedir:

Emoğlu! da'yan diyene kimin Simüzer, at mindi, bının dalénca qōdu "Amcaoğlu! dur, der demez, Simüzer atı binip bunun peşinden kovdu" (Karini, 2009: 199-200).

Türkiye Türkçesi ve Azerbaycan Türkçesi gramerlerinde -AnA zarf-fiil ekinin bağımsız bir zarf-fiil eki olduğuna dair herhangi bir bilgiye rastlanmamaktadır. Cihan Çakmak' in çağdaş Türk lehçelerinde kullanılan zarf-fiil eklerini ele aldığı Birleşik Zarf-Fiil Kavramı ve Çağdaş Türk Lehçelerindeki Görünümleri adlı incelenmesinde de -AnA zarf-fiil eki yer almamıştır (Çakmak, 2013: 13-30). İran Türk ağızları da kapsamlı bir şekilde incelenmediğinden, İran Türk ağızlarının dilbilgisel özelliği genelde Azerbaycan Türkçesi üzerine yapılan

\footnotetext{
** -AnA zarf-fiil ekinin Tebriz, Marağa, Erdebil ve Mişkin ağızlarında kullanılması, kendi gözlemlerimize dayanmaktadır. -AnA zarf-fiil ekinin Halhal Ağızlarında kullanıldığını tespit ettikten sonra Tebriz, Erdebil, Marağa ve Mişkin ağızlarında da söz konusu zarf-fiil ekiyle ilgili incelemelerde bulunduk.
} 
dilbilgisi incelemelerinden hareketle açıklandığından -AnA zarf-fiil ekinin varlığından bahsedilmemiştir. Ayrıca İran'daki Türk ağızları üzerine yapılan incelemelerde de -AnA zarf-fiil ekinin kullanıldığına değinilmemiştir.

-AnA ekinin bir zarf-fiil eki olup olmadı̆̆ -ölçünlü Azerbaycan ve Türkiye Türkçelerinde bir zarf-fiil eki olarak kullanılmadığından- tartışma konusu olabilir. $\mathrm{Bu}$ incelemede -AnA ekinin edat almaksızın bir zarf-fiil eki olup olmaması sorununa, ilk önce bölgeden derlenen metinlerin anlambilimi yönünden incelenmesiyle açıklık getirilecektir. Daha sonra çağdaş Türk lehçe ve ağızlarında kullanılan zarf-fiil eklerinin türeme yolları göz önünde bulundurularak -AnA zarffiil ekinin Türkçenin birleşik-zarf fiil üretme kuralları dâhilinde ortaya çıkıp çıkmadığı tartışılacaktır.

\section{INCELEME}

Zarfların işlevlerinden biri eylemin ne zaman ne şekilde gerçekleştiği ile ilgilidir. Zarf kavramının yukarıdaki tanımı göz önünde bulundurulduğunda derleyip incelediğimiz metinlerde -AnA zarf-fiil ekinin zarf olma durumuyla ilgili herhangi bir kuşku bulunmamaktadır.

Qoca emi ta qutar-ana, bi dene qeméynen virdl. "Yaşlı amca bitirmeden kılıçla bir tane vurdu". Emoğlu! da'yan diy-ene kimin Simüzer, atı mindi, bının dalénca qōdu. "Amcaoğlu! dur, der demez, Simüzer atı binip bunun peşinden kovdu". Arvad, kişi yel-ene ağladı kor oldu. "Kadın, adam gelinceye kadar ağlayıp kör oldu."

Sen gel-ene men yemekleri hazlrraram. "Sen gelinceye kadar ben yemekleri hazırlarım". O yerinnen dur-ana biz şehri çıxdıx. "O yerinden kalkıncaya kadar biz şehri çıktık". Men birin al-ana o ciblerin doldurdu. "Ben bir tanesini alır almaz, o ceplerin doldurdu". On yaşında bir oğlu vardl. Dedesi birin ye-ene, oğlu boşqaptakın qutardl. "On yaşında bir oğlu vardı. Babası bir tane yer yemez oğlu tabaktakini bitirdi."

Azerbaycan Türk ağızlarından Halhal ağızlarında (Karini, 2009: 199-201) -An sıfat-fiil ekinin üzerine -dA bulunma eki getirilerek -AndA birleşik zarf-fiil eki türetilmiştir. Halhal ağızlarında olduğu gibi Kazak, Kırgız ve Tatar leçelerinde de Batı Türkçesinin -An sıfat-fiil ekine denk gelen -gAn sıfat-fiil ekiyle -dA bulunma ekinden oluşan -gAndA zarf-fiil ekinin oluştuğunu görmek mümkündür (Öner, 1998: 232). Kanaatimizce -AndA ve -gAndA zarf-fiil eklerinin oluşum süreci, AnA zarf-fiil ekinin oluşumunda da yinelenmiştir. -An sıfat-fiil eki nasıl -dA bulunma ekini bünyesine katarak -AndA birleşik zarf-fiilini oluşturduysa, -A yaklaşma ekini de üzerine alarak -AnA zarf-fiil ekinin ortaya çıkmasını sağlamıştır. Sıfat-fiil eklerine yönelme veya yaklaşma ekinin getirilmesiyle zarf-fiil ekinin oluşumunu başka Türk lehçelerinde de görebiliriz. Tatar Türkçesinde -r sifat-fiil ekiyle + ga, + ge yönelme ekinden üretilen -rga, -rge zarf-fiil eki bunun tipik bir 
örneğidir (Öner, 1998: 235). Dolayısıyla -An sıfat-fiil ekiyle -A yaklaşma ekinden yeni bir zarf-fiil ekinin türetilmesi Türkçenin birleşik zarf-fiil üretme kuralları dâhilinde gerçekleşmiştir, denebilir.

Men birin al-an-a o ciblerin doldurdu. "Ben bir tanesini alır almaz, o ceplerin doldurdu" cümlesinde Al- fiil köküdür. -an sıfat fiil eki olup üzerine -a yaklaşma ekini alarak al- fiilini zarf-fiil konumuna getirmiştir.

Böylece -AnA zarf-fiil ekinin geniş zaman sıfat-fiil eki -An ile +A yaklaşma ekinden oluştuğunu söylemek mümkündür.

Durum böyle iken Azerbaycan Türk ağızlarında kullanılan -AnA zarf-fiil ekinin edatlı kullanımını nasıl izah etmek mümkündür! -AnA + kimi/kimin zarf grubundan kimi/kimin edatının düşmesi sonucu mu -AnA zarf-fiil eki ortaya çıkmıştır? Yoksa -AnA birleşik zarf-fiil eki, üzerine kimi/kimin edatını alarak genişlemiş midir?

Kazak, Tatar, Kırgız Türkçelerinde -gAn sıfat-fiil ekiyle -dA bulunma hali ekinden oluşan -gAndA zarf-fiil ekiyle (Öner, 1998: 233) Halhal ağızlarında yine An sifat-fiil ekiyle -dA bulunma ekinden oluşan -AndA zarf-fiil ekinin edat almaksızın kullanılması, birleşik zarf-fiil eklerinin herhangi bir edat almaksızın kullanılabileceğinin göstergesidir. Üstelik Tatar Türkçesinde edat alınmaksızın kullanılan -rgA zarf-fiil eki (Öner, 1998: 235) ile Karakalpak Türkçesindeki -rğA; ArğA (Çakmak, 2013: 24) zarf-fiil eki, Halhal ağızlarında kullanılan AnA zarf-fiil ekinin tam karşılığı konumundadır.

\begin{tabular}{|l|l|l|l|}
\hline & Geniş zaman Sıfat-fiili & +Yönelme Eki & $=$ Zarf-fiil Eki \\
\hline Tatar Tür. & $-\mathrm{r}$ & $-\mathrm{gA}$ & - -rgA \\
\hline Karakalpak Tür. & $-\mathrm{r} ;-\mathrm{Ar}$ & $-\breve{g} \mathrm{~A} ;-$ ğ A & - -r̆̆ $\mathrm{A}$-ArğA \\
\hline İran Türk Ağızları & $-\mathrm{An}$ & $-\mathrm{A}$ & $-\mathrm{AnA}$ \\
\hline
\end{tabular}

Dilde en az çaba kanunu kuramınca -AnA zarf-fiil ekinin ortaya çıkmasında -AnA + kimi/kimin zarf-fiil grubu öncülük etmiş olmalıdır. Başka bir deyişle -AnA + kimi/kimin zarf-fiil grubunda yer alan kimi/kimin edatının düşmesi sonucu -AnA zarf-fiil eki ortaya çıkmış olmalıdır. Ancak en az çaba kanunu zarffiil ekleri için geçerli değildir. Zarf-fiil eklerinde genişleme söz konusu olduğundan bir zarf-fiil grubunun küçülmesi düşünülemez (Karahan, 2009: 124-130). Dolayısıyla zarf-fiil eklerinin genişleme eğilimi ile birleşik zarf-fiil eklerinin edat alınmaksızın kullanılması dikkate alındığında -AnA ekinin tek başına bir zarf-fiil eki olduğu, -AnA kimi zarf-fiil grubunun daha sonra ortaya çıktığı söylenebilir. 


\section{SONUÇ}

İran'daki Tebriz, Erdebil, Marağa, Mişkin ve Halhal ağızlarında -AnA eki, bir zarf-fiil eki olarak kullanılmaktadır. İster İran Türk ağızları üzerine yapılan çalışmalarda isterse Türkiye ve Azerbaycan ağızları üzerine yapılan çalışmalarda ve dilbilgisi kaynaklarında -AnA zarf-fiil ekinden bahsedilmez. -AnA zarf-fiil eki, -An sıfat-fiil ekiyle -A yaklaşma ekinden oluşan bir birleşik zarf-fiil ekidir. Söz konusu bölgelerle ilgili derlenen metinler anlambilimi yönünden incelendiğinde AnA ekinin açıkça bir birleşik zarf-fiil eki olduğu görülmektedir. Ayrıca Türkçenin birleşik zarf-fiil eki üretme kurallarıyla çağdaş Türk lehçelerinde kullanılan birleşik zarf-fiil eklerinin yapısı da -AnA ekinin bir birleşik zarf-fiil eki olduğunu desteklemektedir. Ölçünlü Azerbaycan Türkçesinde olduğu gibi söz konusu ağızlarda da -AnA birleşik zarf-fiil ekinin yanı sıra aynı ekin edatla birlikte kullanıldığı da görülmektedir. Zarf-fiil eklerinde vurgudan kaynaklanan genişleme kuramı esas alındığında edatlı yapıların daha sonra ortaya çıktığı düşünülmektedir. Ayrıca çağdaş Türk lehçelerinde geniş zaman sıfat-fiil eki (-r) ile +GA yaklaşma ekinden oluşan -rgA birleşik zarf-fiil ekinin de edat alınmaksızın kullanımı, -AnA zarf-fiil ekinin arkaik olduğunu, edatlı yapıların sonradan ortaya çıktığını destekler niteliktedir.

\section{KAYNAKÇA}

Çakmak, C. (2013). Birleşik zarf-fiil kavramı ve çağdaş Türk lehçelerindeki görünümleri. Dede Korkut Türk Dili ve Edebiyatı Araştırmaları Dergisi, 3 (6): 13-30.

Ergin, M. (2000). Türk dil bilgisi. İstanbul: Bayrak Yay.

Karahan, L. (1996). Anadolu ağızlarının sınıflandırılması. Ankara: Türk Dil Kurumu Yay.

Karahan, L. (2009). "Türkçede şahıs ve işaret zamirlerinin yönelme hâlindeki genişlemeler". III. Uluslararası Türkoloji Kongresi, Ahmet Yesevi Üniversitesi Türkistan.

Karini, J. (2009). Erdebil ili ağızları, Ankara. (Yayınlanmamış Doktora Tezi). Gazi Üniversitesi, Ankara.

Korkmaz, Z. (2003). Türkiye Türkçesi grameri (Şekil bilgisi). Ankara: Türk Dil Kurumu Yay. Yay.

Öner, M. (1998). Bugünkü Kıpçak Türkçesi. Ankara, Türk Dil Kurumu

Öner, M. (1998). -mat1/-meti zarf-fiili hakkında. III. Uluslararası Türk Dil Kurultayl, Ankara: Türk Dil Kurumu Yay. 